\section{Constructing the self}

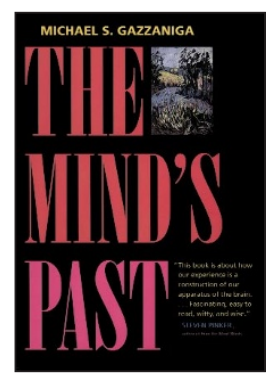

The Mind's Past

by Michael Gazzaniga

University of California Press, 1998. $\$ 22.50$ hardcover, pp216

ISBN 0-520-21320-3

Reviewed by Antonio R. Damasio

The attempt to understand the neural underpinnings of human cognition began about a century and a half ago, with the discovery that language processing depended on the left cerebral hemisphere. Comparable discoveries followed, but it was not until the last three decades that a loose coalition of disciplines interested in these issues came into its own and began expanding as a field. The field is known as cognitive neuroscience, and its spectacular development over the past few years has been due to the practical and theoretical maturity of psychology and neurobiology, along with the advent of major advances in neuroimaging.

Hardly a month goes by without some interesting new finding being reported in one of the major scientific journals, and hardly a year ends without some important discovery clarifying one of the significant problems facing us in this broad field. The progress is so voluminous that it is difficult to keep abreast of all that is noteworthy, even for those who are direct contributors. This is no doubt more of a problem for those, scientists and not, who are outside of the field looking in. Observers need all the help they can get to sift through new findings and new interpretations and to be able to situate them in the rapidly evolving panorama of science. This is one reason why Michael S. Gazzaniga's new book, The Mind's Past, is a useful contribution.

As one might expect, given the origins of the field, progress in cognitive neuroscience has been uneven, pulled sometimes by a new breakthrough of technology - as is the case with positron emission tomography and functional magnetic resonancepulled other times by a new theoretical development, for instance, neural nets. Not surprisingly, the conceptualizations behind

Antonio R. Damasio is M.W. Van Allen Professor and Head, Department of Neurology, University of Iowa College of Medicine, Iowa City, Iowa 52242, USA

email: cmdard@umaxc.weeg.uiowa.edu the progress have been varied. For much of the recent heroic period, the brain has been seen through the eyes of the computer metaphor, and its biological setting has often been ignored. Nowhere is there a stronger sign of this imbalance than in the relative neglect of an evolutionary perspective in this entire field. Of late, the balance has begun to change, and both brain and mind phenomena are now more frequently seen in terms of their possible evolutionary antecedents. Nonetheless, Gazzaniga is aware of the need to endorse this conceptual trend, argues for its advantage and uses it as a backbone to his book.

Gazzaniga's new book is neither a catalogue of new discoveries nor a textbook of cognitive neuroscience. Gazzaniga's aim is to take a number of unresolved issues, highlight dominant views and prevailing findings, and close the commentary with a personal view, often in the form of a strong opinion. In topics ranging from brain development to the relative contributions of learning and inheritance, to the role of nonconscious processing in conscious experience, and to the creation of false memories, Gazzaniga underscores the controversy and takes sides, relying on both hard data and rhetoric to make his case. Gazzaniga seeks to stir up and provoke, and succeeds.

The Mind's Past is not meant as a reference source. You will not find, say, a description of facts with which to decide on the issue of nature versus nurture in human behavior. Yet the book is an accessible way to discover what a founding member of cognitive neuroscience thinks on that and other matters, and perhaps to begin further explorations.

I read the book in one sitting, and found myself agreeing with a good number of the points Gazzaniga makes. His emphasis on the outstanding power of nonconscious processing is right on the mark, and he gives the reader a capsule of some of the most exciting new results in this area. In general, I also liked his views on what he calls "the fictional self." When it comes to the high-level constructions we make about our own lives, and when we make use of the knowledge contained in what I call the 'autobiographical self,' we often create fiction. Gazzaniga had first-hand experience with the basis for this phenomenon when he studied splitbrain patients, as the left hemisphere of those patients is nothing if not a fabulist story teller. He suggests that the view of ourselves that we fabricate can contain as much fiction as truth.

Still, I am not with Gazzaniga all the way on the matter of consciousness. Shortly after the beginning of the book, on page 1, Gazzaniga writes, "The brain, particularly the left hemisphere, is built to interpret data the brain has already processed. Yes, there is a special device in the left brain, which I call the interpreter, that carries out one more activity upon completion of zillions of automatic brain processes." Although I am not enthusiastic about the notion of interpreter-how does it get empowered to interpret? How does it reason the interpretation?-I can find ways around this problem. Without a doubt, something like an interpretative process goes on at this high level of neural business, and it relies heavily on language. My problem is with another idea, with which Gazzaniga closes his book, on page 175. He states, "The insertion of an interpreter into an otherwise functioning brain delivers all kinds of by-products. A device that asks how infinite numbers of things relate to each other and gleans productive answers to that question can't help but give birth to the concept of self. Surely one of the questions the device would ask is "Who is solving these problems?" Call that "me," and away the problem goes!"

With one simple stroke, Gazzaniga dismisses the problem of self and consciousness, and this is where I have reservations. Much as I believe that a language-based process does contribute to consciousness at the high end and frosts its cake, so to speak, I doubt consciousness can be explained this easily. Notwithstanding the fictional and not-so-fictional interpretations at the top of the hierarchical mechanics of consciousness, I believe that a multilayered, languagefree, organism-based specific neural device actually constructs several aspects of self and of consciousness. The good news is that empirical evidence will decide the issue, not philosophical argument. The state-of-theart, as covered in Gazzaniga's book, suggests that we will be able to resolve many arguments in this field on the basis of experimental evidence, and that is cause for celebration. 